\title{
A formação humana na Educação Superior: abordagem onto-antropológica e teológica de Edith Stein
}

\author{
Human formation in higher education: \\ Edith Stein's onto-anthropological and theological approach
}

\author{
Clélia Peretti* \\ Vera Fátima Dullius**
}

\begin{abstract}
Resumo
O artigo reflete sobre o atual contexto da Educação Superior e seus desafios na formação de novos perfis de docentes. Optamos por indagar fenomenologicamente a formação docente em uma instituição confessional a fim de perceber, na pulsão das vivências dos estudantes, o lugar que a formação humana e da consciência ocupa na trajetória acadêmica. Seguindo essa pista e dialogando com profissionais e estudantes percebemos a necessidade de um maior aprofundamento dos pressupostos antropológico-filosóficos da educação. A partir disso, fizemos um contraponto entre o modelo reducionista e o complexo, fundamentando as concepções de conhecimento e educação no diálogo entre dois grandes pensadores: Edith Stein (19811942) e Edgar Morin (1921-). Os resultados revelam a necessidade de um diálogo multi e transdisciplinar nos programas de formação docente, bem como a necessidade de pensar a formação humana a partir do paradigma da complexidade, interligando saberes que fomentem a reforma do pensamento. A formação humano-integral requer projetos que incluam todas as dimensões do ser humano. Desse modo, o ato educativo, ensino e aprendizagem, assume proporções que ultrapassam a experiência de sala de aula e perduram em sua formação. A reflexão realizada fez emergir com maior clareza os desafios de nosso tempo: um pensar rigoroso sobre o "humano" e sua formação em uma perspectiva onto-antropológica que tenha como base uma visão de mundo, de ser humano e de transcendência comprometidos com valores pautados na ideia de "casa comum".
\end{abstract}

Palavras-chave: Educação Superior. Formação Humana. Complexidade. Edith Stein. Edgar Morin.

\begin{abstract}
The article reflects on the current context of Higher Education and its challenges in the formation of new teaching profiles. Here, we chose to phenomenologically inquire about teachers' education in a confessional institution in order to perceive, in the pulse of the experiences of undergraduate students, the place human and conscience formation occupies in academic trajectory. Following this lead and dialoguing with professionals and students, we realized the need for a deeper understanding of education anthropological-philosophical assumptions. Based on that and stemming from the conceptions of knowledge and education in the dialogue between two great thinkers, Edith Stein (1981-1942) and Edgar Morin (1921-), we counterpoint reductionist and complex models. The results reaffirm the need for a multi and transdisciplinary dialogue in teachers' education programs, as well as the need to think about human education from the complexity paradigm, linking together knowledges that may foster the renovation of thought. Human-integral training requires projects that include all dimensions of the human being. In this way, the educational act, teaching and learning, assumes proportions that may go beyond classroom experience and persist in their formation. This reflection made the challenges of our time emerge with greater clarity: a rigorous thinking about the "human" and its formation in an onto-anthropological perspective that is based on a vision of the world, of human being and of transcendence that is committed to values guided by the idea of a "common house".
\end{abstract}

Keywords: Higher Education. Human Formation. Complexity. Edith Stein. Edgar Morin.

Artigo submetido em 28 de novembro de 2019 e aprovado em 15 de abril de 2020.

* Doutora em Teologia pelas Faculdades EST. Professora da PUCPR. País de origem: Brasil. E-mail: cpkperetti@gmail.com

** Doutora em Teologia pela PUCPR. Professora da PUCPR e do UNIFAE. País de origem: Brasil. E-mail: veradullius@gmail.com 


\section{Introdução}

A Educação Superior brasileira encontra-se envolta em uma teia complexa de desafios. Crescem às demandas do mercado, aumenta a tensão entre o acesso, a qualidade e a concorrência entre as Instituições de Educação Superior a serviço de sua missão e aquelas que transformam a educação em mercadoria. Soma-se a tudo isso, a forte influência das forças globais tais, como: o impacto das tecnologias na formação dos perfis profissionais; a obsolescência programada e o lançamento de novos produtos agregados a demanda por empregabilidade. Além disso, intensifica-se a globalização de padrões culturais; as fakes news nas redes sociais; a banalização da violência; o aumento do fosso das desigualdades intra e entre países, pandemias, desmantelamento de direitos sociais e outros fatores que tecem os fios dessa teia. O contexto atual, portanto, tende a evidenciar ambiguidades, paradoxos, fragilidades dos antigos paradigmas, fazendo surgir novos cenários e a manifestação de novos protagonistas tanto presenciais quanto virtuais. Nesse sentido, estamos diante de uma realidade cada vez mais incerta e complexa, em que as lideranças, por vezes, sentem-se perdidas, buscando respostas imediatas, mas, se deparam com a dificuldade de não conseguir estabelecer relações com as decisões locais (HARARI, 2018) e com abordagens multi e transdisciplinares. Diante dessa complexidade ${ }^{1}$ impõe-se a emergência de uma formação mais humana, baseada na "reforma do pensamento" (MORIN, 2000) e num novo sentido de pertença à comunidade.

Diante disso, optamos, neste artigo indagar fenomenologicamente a formação docente em uma instituição confessional ${ }^{2}$ a fim de perceber, na pulsão das vivências dos estudantes formandos, o lugar que a formação humana e da consciência ocupa na trajetória acadêmica. Seguindo essa pista e dialogando com profissionais e estudantes, percebemos a necessidade de um maior

\footnotetext{
${ }^{1}$ Complexus significa o que foi tecido junto. De fato, há complexidade quando os elementos diferentes são inseparáveis constitutivos do todo e, ainda, quando há um tecido interdependente, interativo e inter-retroativo entre o objeto de conhecimento e seu contexto, as partes e o todo, o todo e as partes, as partes entre si. Por isso, a complexidade é a união entre a unidade e a multiplicidade (MORIN, 2000, p. 38).

${ }^{2}$ Os resultados dessa pesquisa foram subsidiados pelo Parecer consubstanciado do Comitê de Ética em Pesquisa CEP. Parecer $n$. 2.266.597. Curitiba 11 de setembro de 2017.
} 
aprofundamento dos pressupostos antropológicos-filosóficos da educação. A partir disso, fizemos um contraponto entre o modelo reducionista e o complexo, fundamentando as concepções de conhecimento e educação no diálogo entre dois grandes pensadores: Edith Stein (1981-1942) e Edgar Morin (1921-).

Os escritos de Edith Stein contribuem para fundamentar a criação de uma proposta atenta aos desafios da formação superior docente no Brasil, especialmente nas instituições confessionais cristãs, que por imperativo de sua missão, agregam uma releitura de sua identidade. Para tal, utilizou-se o método fenomenológico (HUSSERL, 2001) contextualizando-o no campo da educação (VAN MENEN, 2003). A contribuição de Edith Stein foi ampliada com o diálogo com outros pesquisadores, de modo particular com Angela Ales Bello (2004, 2014, 2016, 2017, 2018), filósofa e uma das renomadas pesquisadoras do pensamento de Edith Stein.

A proposta de Morin nos convida a sairmos das ruinas da edificação construídas sob os pilares da fragmentação, hiperespecialização e redução do saber. O autor enfatiza a necessidade de abrir as "gavetinhas" nas quais os saberes estão arquivados, para que, então, possamos tecer os saberes de forma complexa. De tal maneira, o paradigma da complexidade coloca-se como uma proposta integradora dos diferentes saberes Morin (2005). A partir do momento em que os sujeitos são entendidos como seres inacabados e se constroem ao longo da vida, é fundamental pensá-los desde a complexidade humana, uma vez que são seres biológicos e culturais. Esta complexidade constitui a possibilidade de ampliar o pensamento sobre o mundo e a vida e, junto a isso, a possibilidade de enfrentar os desafios à fragmentação dos saberes humanos, científicos e da tecnologia. Trata-se, portanto, de perceber o mundo a partir de uma nova perspectiva. Todos os elementos que compõem a realidade são inseparáveis e constitutivos do todo. Há uma interdependência entre o objeto do conhecimento e seu contexto, "as partes e o todo, o todo e as partes, as partes entre si" (MORIN, 2001, p.38). No contexto de crise paradigmática a teoria da complexidade de Edgar Morin nos inspira a mapear, entender e reconstruir passos no encontro entre ciência, tecnologia, 
sociedade, ser humano e planeta. O grande esforço não consiste em investigar a competição entre as diversas áreas, mas integrá-las, para que caminhem próximas, entrelaçadas, questionando seu papel para as próximas décadas. É inadiável a introdução de um pensamento capaz de articular as diferenças, as desigualdades, cuja tônica é aprender conviver com a contradição e, aprender estabelecer um diálogo entre a ordem e a desordem, a certeza e a incerteza, que embora antagônicos se fazem complementares.

Dessa maneira, percebe-se a necessidade de uma formação que considere a complexidade como princípio pedagógico e pressuposto de todo conhecimento. $\mathrm{O}$ desenvolvimento técnico científico dos dois últimos séculos, além de provocar uma crise antropológica afetou também o sistema educacional, as práticas pedagógicas, a organização das instituições de ensino e de seus currículos. Essas mudanças levam a repensar a formação dos profissionais da educação exigindo a superação, a fragmentação e a reprodução mecânica do conhecimento em suas práticas pedagógicas. Igualmente, o conhecimento entendido como provisório e incerto deve ser refletido, criticado, sistematizado, apreendido pelo próprio discente, a fim de que se torne sujeito ativo na construção de sua aprendizagem. Nesse sentido, é fundamental repensar a formação docente a partir do paradigma da complexidade, articulando-a com a proposta steiniana de formação e educação. A vivência e as contribuições teóricas propostas pela autora são vitais para compreender e repensar as atitudes essenciais da formação docente. A vivência na educação nos abre à percepção de um ser humano que se desenvolve educando-se e, nos remete à fenomenologia genética pois essa contribui para compreender a constituição do ser humano em suas diferentes dimensões. Os resultados apresentados a seguir respondem afirmativamente que é possível pensar um projeto de formação humana na Educação Superior e, reafirmam a necessidade de um diálogo multi e transdisciplinar, bem como a necessidade de uma fundamentação antropológicofilosófica e teológica do fenômeno educativo. 


\section{Elementos teóricos para o pensar a formação humana}

A universidade, nas últimas décadas, passa por um processo de redefinição de sua identidade. Elas investiram nos processos de gestão, profissionalização, mudanças de modelos pedagógicos, de inovação e qualidade, alinhando-se às demandas do mercado. Entre os desafios coloca-se a formação de novos perfis capazes de acompanhar as mudanças advindas dos avanços científicos e tecnológicos. A compreensão que perpassa a lógica do mercado parte do pressuposto de que o ser humano é apenas razão, corporeidade e vontade, excluindo, assim, a dimensão humana e a dimensão da transcendência. Ao lado dessas tendências colocam-se pensadores que alertam para a emergência do humano em sua integridade e defendem a importância da afetividade, da espiritualidade e da mística. A seguir, evidencia-se a necessidade de programas e espaços acadêmicos para refletir sobre a constituição da pessoa, sua estrutura e seu ser, seu lugar na história. Veremos que é a partir da reflexão sobre o ser, sobre suas relações com os outros e sus significações que o ser humano desenvolve sua identidade no reconhecimento da alteridade e compreende o sentido da relação com o transcendente.

\subsection{A instituição de Educação Superior confessional e o papel da Igreja na formação}

Desde a sua origem a universidade teve como objetivo a formação da pessoa e sua inserção na sociedade. A cada época utilizou-se métodos e abordagens pedagógicas diversificadas. Na Idade Média, por exemplo, no tocante à parte pedagógica, foram adotadas a lectio (a leitura) e a quaestio (o questionamento). Já em meados do século XIII, a universidade com a ação da Igreja contribui para a formação de novos domínios para lidar com os desafios "da produção agrícola e as relações estabelecidas entre senhor e servo, a arte da guerra e a catequese oral" (PASSOS, 2018, p.2). As chamadas universitate também contribuíram para pensar as relações do mundo imanente e transcendente e tecer respostas às novas ciências que surgiam na Europa. A Igreja oferece na origem das universitate as bases de sua 
missão: estudar, pesquisar, investigar, como meio para chegar à verdade. Na Idade moderna e de modo particular no Brasil com a chegada dos primeiros padres jesuítas, em 1549, inaugura-se a primeira fase da história da educação brasileira. Assim, desde o período da colonização, o ensino e a aprendizagem que tiveram forte influência europeia no seu planejamento e na sua formalização sofreram grandes transformações.

Em 1907, John Henry Newman (1901-1990) apresentava reflexões contundentes sobre o papel da universidade na constituição de um corpo de saberes orientados para a formação humana aliada a formação profissional. Na sua busca apaixonada pela verdade, recorda-nos em seus escritos e pregações, a necessidade do diálogo entre fé, ciência e cultura. Ao fundar a Universidade Católica de Dublin, na Irlanda, Newman estava convencido de que não podia haver conflito entre religião e ciência, uma vez que a ciência não pode ser contrária à verdade. Tratou também, da questão das razões de crer de quem tem fé em Deus. Incentivou os cristãos leigos a participarem das responsabilidades da vida e da missão da Igreja. Newman ensinava que todos deviam seguir com fidelidade a luz tênue da verdade que se manifestava por meio da consciência. Rumayor relata que para Newman, a universidade deve estar alinhada com os desafios da sociedade. Se a universidade não está alinhada "ela é inútil, então ela tem que preparar as pessoas para o que elas precisam" (2019, p.318). Para o autor, Newman, sustenta que a formação universitária deve proporcionar condições de busca da verdade e este processo não se faz de forma individual, mas coletivamente e como instituição de pesquisa e de ensino. Acrescenta-se, que a busca da verdade não está desconectada com a realidade da vida, pois não há como fazer uma verdadeira formação acadêmica sem uma visão ampla e crítica da realidade e da natureza do ser humano. Portanto, há que se buscar fundamentos antropológico-filosóficos e teológicos para essa proposta. Para Newman, o grande desafio da universidade consistia em transformar-se em “alma mater" a fim de que pudesse nutrir, oferecer elementos para que a pessoa se desenvolve-se de forma plena (RUMAYOR, 2019). A proposta educativa de Newman rompia com os paradigmas educativos vigentes na época. Deste modo, Newman compreende que a 
educação é o que dá ao homem uma visão consciente de seus próprios juízos e opiniões, bem como a verdade para desenvolvê-los, a eloquência para expressá-los e a energia para os propor. Ensina você a ver essas coisas como elas são, a ir direto ao núcleo, a endireitar um nó de pensamento, a detectar sofismas e a eliminar o irrelevante. Ela prepara você para realizar qualquer trabalho com altura e dominar qualquer assunto com facilidade. (NEWMAN, 2001, p. 186).

Os escritos de Edith Stein estão em sintonia com o pensamento de Newman. Ela traduziu entre os anos 1923-1924 a obra "Ideia de Universidade" do autor, assim como seu diário e correspondências (RUS, 2015). Desse modo, compreendese que a educação sempre ocupou um lugar privilegiado para formar o ser humano e, a Igreja sempre apoiou as instituições educativas, como lugar de diálogo entre cultura, ciência e fé e, ainda, como locus de busca pela verdade e honestidade intelectual. Para o cardeal Newman era necessário combater o relativismo intelectual e moral, enquanto enfraquecia os fundamentos da cultura e do convívio social. Ele motivava teólogos e filósofos a dialogar com todos na busca árdua e aprofundada de uma verdade que liberta. Do mesmo modo, Edith Stein buscou desenvolver uma fundamentação antropológico-teológica para a educação. Ela estava consciente de que o processo de formação da pessoa articula dinâmicas internas e vivências externas. O "mundo-da-vida", ou seja, as vivências cotidianas, o processo de individuação são exigências inerentes a pessoa humana. De tal modo, cabe às organizações da sociedade (família, igreja, escola-universidade e estado) o papel de realizar mediações pautadas na verdade, na ética e na responsabilidade. (STEIN, 2017). A consciência do papel educativo levou Edith Stein a ampliar seu compromisso com a proposta de uma formação humano-integral da juventude e, de modo particular, de mulheres que almejavam exercer a função de professoras.

Edith Stein compreende a educação como um gesto de criação, de liberdade do indivíduo resultante por um lado, das energias de que ele dispõe originariamente e, do outro, de um conjunto de experiências que atuam exterior e interiormente. Embora, Edith Stein, vivesse num contexto fortemente marcado pelo regime nazista, ela afirmou corajosamente a necessidade de as instituições 
oferecerem uma educação cristã (STEIN, 1999). Ela se inspirou na pedagogia universitária proposta por Newman cujas características eram: clareza quanto a ideia de ser humano; liberdade de pensamento; necessidade de conhecimentos universais; relação do conhecimento com a vida; múltiplos saberes universitários; referência aos mestres; valorização do método e conscientização de que o acesso aos conhecimentos em níveis diferentes de aproximação e de aprofundamento. (MARTÍN-SÁNCHEZ, CÁCERES-MUÑOZ, 2015). Complementa Stein à Newman, as forças do ser humano "requerem orientação e direção; é esse o lugar do trabalho da formação, para instrução e educação consciente livre.” (STEIN, 1999, p. 117). Mulher de consciência, Edith Stein contribuiu para com a ampliação, a sistematização da formação e a criação de escolas de formação pedagógica na Alemanha. Nesse sentido, destaca-se sua atuação no iminente contexto nazista alemão, onde afirma corajosamente a necessidade do direito das instituições em oferecer uma educação cristã (STEIN, 1999).

Edith Stein compreende o ser humano na sua multidimensionalidade: corpo (Leib), espírito (Geist), psique ${ }^{3}$ e alma. Nas suas análises fenomenológicas da dimensão psíquica, define a consciência como profundidade e interioridade humana que, sabendo-de-si, pode exercer a sua liberdade e relacionar-se com o outro na sua singularidade. Este conceito 4 está "intimamente ligado ao que ela define como núcleo (Kern) da pessoa humana" (ALFIERI, 2014, p. 63). A liberdade "é uma atividade espiritual" (ALES BELLO, 2004, p. 114) e torna-se o motor principal do processo formativo. Sendo assim, o cuidado para com o "humano" cabe a todas as instituições. Na conferência de 1931, sobre a missão dos intelectuais, enfatiza o papel estratégico e a mediação que esses devem exercer na “educação e formação do povo" (STEIN, 2017, p. 225). O “intelectual” não se ocupa somente com pesquisas teóricas, mas deve ocupar-se também com o exercício da ação formativa (STEIN, 2017), pois "quanto o intelecto se desenvolve, maior é a

\footnotetext{
${ }^{3} \mathrm{O}$ termo psique é importante para a compreensão fenomenológica steiniana. Segundo Ales Bello este conceito deriva da língua grega e latina e significa anima, ambas as palavras possuem origem na antiga língua indo-europeia e significam "sopro", "respiro", no sentido de sopro e respiro cósmicos (2016, p.25). Para Alfieri o termo "o espírito (Geist), refere-se a dimensão intelectiva, pois se abre aos valores e aos sentimentos etc." (2014, p. 63).

${ }^{4}$ É fundamental compreender o termo "conceito" que em Stein significa "essência". "O conceito é formado para determinar o objeto. A essência é encontrada vendo o objeto [...] o conceito pressupõe a captação da essência. É aí que se nutre a formação do conceito." (STEIN, 1988, p.111).
} 
possibilidade de ação.” (STEIN, 2017, p. 225). Os intelectuais são corresponsáveis pelos destinos da sociedade (STEIN, 2017), pelo desenvolvimento da singularidade e da capacidade empática de viver em comunidade. (STEIN, 2017). Assegura-se, deste modo, que a universidade é um lugar privilegiado de formação humana e profissional, ainda, é um espaço de educação para uma consciência ética e política. Em seus escritos Stein resgata o sentido de pertencimento à mesma comunidade humana, à mesma diversidade. Nisso, Morin (2007, p. 58) corrobora dizendo: "temos necessidade de sentido e este sentido aponta para o desenvolvimento dos sentidos ético e político e de reforma epistemológica, em essência uma reforma do pensamento." (MORIN, 2007, p. 58).

Constata-se, destarte, a necessidade de atualizar os modelos pedagógicos a partir das demandas da sociedade. O sujeito não desenvolve suas competências apenas com a interiorização do conhecimento, mas ele precisa internalizá-las mediante recursos cognitivos, no desenvolvimento de competências que possibilitem a mobilização dos conhecimentos a situações e vivências diversificadas. Cabe ressaltar que já na sua época Edith Stein era atenta a proposição e ao uso de "métodos ativos" (STEIN, 1999, p.147), considerados fundamentais no processo de ensino e aprendizagem e para a formação da consciência.

\section{A formação do humano e da consciência em Edith Stein}

A formação5 (Bildung) assume em Edith Stein uma conotação inovadora em seu tempo, pois essa articula no seu processo a formação mediada e a autoformação. Para Stein o ser humano tem como desafio formar-se por inteiro: corpo, espírito (intelecto) e alma (essência). (STEIN, 2017). Mas, a formação ${ }^{6}$ só terá sustentação se contar com uma clara visão de quem é o ser humano (RUS, 2015). Para o autor, Edith Stein estabelece uma clara distinção entre educação e formação.

\footnotetext{
${ }^{5}$ Formar e modelar um material afim dar-Ihe uma formar, com e base em modelo (STEIN, 2017, p.65).

6 " [...] entendimento do que se deva entender por formação: o processo (ou o trabalho) que confere à aptidão da alam uma configuração moldada (costuma-se falar também em formação como resultado desse processo)." (STEIN, 1999, p. 118-119).
} 
A formação do espírito é particularmente incumbência do ensino. Sob a denominação de ensino Edith Stein inclui duas coisas: de um lado, a formação do espírito em sua atividade cognitiva (intellectus) e em sua capacidade de atingir percepções claras, conceitos corretos e julgamentos verdadeiros; de outro lado, a transmissão e assimilação viva de um patrimônio cultural. (RUS, 2015, p. 62).

Dessa maneira, compreende-se que o desenvolvimento da individualidade e da singularidade é um processo fundamental. De acordo com Alfieri (2014, p. 31): a "antropologia de Edith Stein parte da vida humana real para compreender o ser humano [...] o ponto de partida é sempre a vida em sua densidade”. Em seus estudos, mostra que a estrutura ontológica do ser humano é complexa, formada por duas realidades aparentemente inconciliáveis: natureza e espírito. Essas realidades não são isoladas, mas intimamente articuladas entre si: não podemos habitar no nosso corpo se não fossemos habitados por uma força espiritual. Edith Stein identifica na singularidade um núcleo essencial, e para alcançar esse núcleo é preciso "reconhecer a própria identidade, o que nos possibilita um contínuo recomeçar a partir do que verdadeiramente somos." (ALFIERI, 2014, p. 15). Não somos apenas frutos do ambiente social e de nossas decisões. A pessoa "tem a possibilidade de crescer quando explora o seu verdadeiro potencial e toma plena consciência de si mesma, chegando ao núcleo de sua personalidade" (ALFIERI, 2014, p. 15). Para Edith Stein o princípio de individuação7, é conjugando entre o método fenomenológico e a filosofia medieval. Ela estuda o processo de individuação da pessoa humana com base nos diversos níveis de estratificação. $O$ problema da individuação diz respeito ao processo de desenvolvimento da pessoa, no tempo e espaço histórico, enquanto processo de tornar-se si mesmo. O processo de individuação, é concebido como passagem de uma essência que se atualiza e se realiza no contínuo ato existencial da vida-no-mundo. Esse processo inclui, também, a experiência de espiritualidade, pois o viver no mundo exige transcendência de si em direção ao sentido da vida.

\footnotetext{
${ }^{7}$ Pensar em ontologia da individuação, então, é pensar no ser da natureza universal de onde advêm os entes individuais. A síntese de epistemologia do conceito que Edith Stein faz segue este roteiro desde suas raízes na antiguidade clássica em termos e expressões gregas, depois passando à sua apreensão pela filosofia cristã medieval no estudo do princípio que o orienta o processo de entidade (principium individuationis), especialmente na metafísica cristã escolástica de Tomás de Aquino.
} 
Em sua tese de doutorado sobre O problema da Empatia (1992), Stein propõe uma antropologia filosófica baseada na noção de singularidade, oposta a visão naturalista e positivista. Deste modo, introduz na análise da essência da empatia, uma antropologia filosófica "não construída sobre o ideal do que seria uma pessoa, mas sobre a experiência de ser pessoa.” (ALFIERI, 2014, p. 18). Em seus escritos, a autora propõe a passagem de uma filosofia antropocêntrica na perspectiva da fenomenologia husserliana para uma filosofia antropoteológica na ótica da metafísica cristã, de Tomás de Aquino, Agostinho e Duns Scoto. Ela aprofunda o conceito de individuação na perspectiva ôntica e ontológica, contemplando tanto a sua dimensão individual quanto coletiva.

A investigação sobre a individuação, articula, ainda, o tema da formação e da autoformação. A formação ocorre por meio de um processo individual e social (STEIN, 2017). Busca-se empreender na liberdade 8 o formar-se a partir das próprias vivências 9 , escolhendo o que pode ser conteúdo de formação pessoal a partir dos valores que se deseja alcançar (STEIN, 2017). Logo, o ambiente educativo é, por excelência, um espaço que "inclui forças morais de grande valor que podem ser frutíferas do ponto de vista educacional.” (STEIN, 2017, p. 187). O itinerário formativo dá-se na ativação da consciência, de si-mesmo; da presença do outro como totalmente outro (alteridade); das relações com a família, a sociedade, comunidade, estado e com a transcendência. Stein assevera que esse caminho é composto por dois movimentos: a interioridade e a empatia (STEIN, 2017).

\subsection{Da percepção sensível à relação empática}

O despertar da sensibilidade acontece no ato de ativar os sentidos na relação consigo, com o outro, com o "mundo-da-vida"10 e com o transcendente. ${ }^{11}$ Educa-se o olhar, o sentir, o perceber, o ouvir de forma ativa no mundo. Por essa razão, Stein

\footnotetext{
8 “A pessoa livre é consignada a si mesma, ou seja, o corpo e a alma são submetidos - mesmo que não de forma incondicional - à orientação da vontade." (STEIN, 2017, p. 68).

${ }^{9}$ As vivências são: "a reflexão, a lembrança, a memória, a imaginação, a fantasia." (ALES BELLO, 2004, p. 50).

${ }^{10} \mathrm{O}$ mundo-da-vida é, assim, todo o conjunto de saberes e práticas de sentido implícito (incorporado, diríamos hoje) que constitui a esfera essencial de sentido da consciência e que, enquanto tal, é o pressuposto sempre dado por descontado da ciência, muito frequentemente, dá vazão ao seu mundo matematizado como se ele fosse o verdadeiro mundo). (ALFIERI, 2014, p. 26).

11 "Deve-se propor a busca da verdade que motive o ser humano ..." (STEIN, 1999, p. 122) e conduza a desenvolver-se, relacionar-se consigo, com o outro e com o mundo.
} 
sustenta que tanto a formação dos outros quanto a própria depende de uma "visão de mundo" (STEIN, 1999, p.119), das interações e afetividade. ${ }^{\mathbf{2}}$ A afetividade "leva a assumir determinadas posições e ajuda também a formar a capacidade de discernimento.” (STEIN, 1999, p.123).

A percepção, a intuição sensível13, possibilita a abertura à vida, ao outro e remetem a uma relação de empatia ${ }^{14}$ ou entropatia (Einfühlung). (STEIN, 1992), compreendida como "sentir imediatamente que estamos em contato com outro ser humano, de modo tal que podemos falar 'nós'." (ALES BELLO, 2017, p.60). A relação empática contribui, ao mesmo tempo, na constituição do eu. Ales Bello diz:

o outro suscita em mim o confronto com aquilo que me é dado na percepção interna, possibilitando-me adquirir sempre mais a consciência de mim mesmo através de uma reflexão contínua que pode ter também uma função de corretivo de eventuais enganos. (2014, p.55).

Sendo assim, a relação empática possibilita o encontro com a própria verdade e com o si-mesmo. Este é um elemento didático-pedagógico fundamental na formação humana que requer um novo perfil de professor, que por sua vez, se atualize, se inove, não tenha receio de se expor e ser ele mesmo. A tomada de consciência é o que permite a transformação da pessoa e de suas ações. De acordo com Morin (2001) é preciso saber reelaborar, reconstruir, ceder, observar e se perceber frágil em diversos pontos, um exame doloroso, mas necessário, para o crescimento pessoal e que traga e leve os reflexos para a vida em sociedade. Enquanto profissionais da educação precisamos entender a complexidade, com sensibilidade, - seja ela inata ou buscada, trabalhada, aperfeiçoada - desde à cultura à herança genética cósmica que possuímos.

\footnotetext{
12 "São as emoções da vida que movimentam o nosso ânimo e, para despertá-lo, é necessário pô-lo em contato com algo que emocione." (STEIN, 1999, p. 122).

${ }^{13} \mathrm{O}$ que se chama de intuição tem muito a ver com aquilo que a filosofia tradicional denomina de abstração. (STEIN, 1999, p. 193).

${ }^{14}$ A palavra alemã utilizada por Husserl (Einfühlung) é composta por três partes, o núcleo 'fühl significa 'sentir'. Há na língua grega uma palavra que poderia corresponder a fühl (e a feeeling, derivada da língua latina): pathos, que significa 'sofrer' e 'estar perto'. (ALES BELLO, 2017, p. 63).
} 


\subsection{Pertença social e cooperação cidadã}

O ser humano em sua condição originária e reflexiva (ALES BELLO, 2004), sabe de si, sabe da vida, da presença dos outros e interage com a comunidade e com outras pessoas que também possuem uma sua individualidade própria. ${ }^{15}$ (STEIN, 2017). De tal modo, o sentido de pertença resulta ser uma disposição que transversaliza as semelhanças e as diferenças de todos os seres humanos unindo-os em um só como humanidade. (ALES BELLO, 2018). Esse processo se dá na reflexão enquanto "capacidade de examinar toda a estrutura do sujeito humano." (ALES BELLO, 2004, p.51). Do mesmo modo, Morin (2001) assinala que a educação do futuro deverá ter o ensino centrado na condição humana e ainda reconhecer sua diversidade cultural inerente, pois todo conhecimento deverá situar o humano no universo; contextualizar seu objeto e responder as questões essenciais da vida. O ser humano traz consigo o enraizamento e o desenraizamento das condições cósmicas, físicas, terrestres e a condição humana, quando nesta última o papel da hominização é destacado como primordial à condição humana.

A complexidade humana não poderia ser compreendida dissociada dos elementos que a constituem: todo desenvolvimento verdadeiramente humano significa o desenvolvimento conjunto das autonomias individuais, das participações comunitárias e do sentimento de pertencer à espécie humana. (MORIN, 2001, p. 55).

O estado, a sociedade e a vida em comunidade (Gemeinschaft) ${ }^{16}$ são essenciais para o desenvolvimento da pessoa (STEIN, 1993), para sua hominização. (MORIN, 2001). Essas contribuições sobre o futuro da humanidade são pertinentes e podem contribuir também para iluminar a realidade brasileira (SOUZA; MEDEIROS, 2017), pois inúmeras situações conclamam por "humanidade" e por "hominização", dentre estas destacamos: o tráfico humano; a escravidão; a exploração sexual de crianças e adolescentes; doenças; pandemias; fome; pobreza; discriminação de gênero etc. Deste modo, a educação deverá se preocupar com a

\footnotetext{
${ }^{15} \mathrm{~A}$ individualidade reside no lugar originário do viver o eu, a partir do qual o indivíduo desperto pode sentir que cada vivência apreendida do centro do seu ser, é portadora de uma singularidade própria; é isso que o distingue dos outros. (ALFIERI, 2014, p. 75).

${ }^{16}$ Stein privilegia sempre, em todas as suas obras, a correlação eu-outros, considerando que a existência da pessoa humana está sempre inserida no mundo, num convívio comunitário. (ALFIERI, 2014, p. 89).
} 
formação do cidadão, da pessoa em seu sentido amplo, e não somente com a formação profissional. O ser humano é complexo e compreendê-lo exige muita reflexão, apreensão de suas vivências, compreensão dos sofrimentos, acreditar na possibilidade de cada um de autoformar-se. É preciso, portanto, estar aberto aos outros, interiorizar o respeito, a aceitação de ideias, escolhas e posições divergentes. Sobre isso, Morin nos ensina que a compreensão do outro exige formar-se para uma nova consciência: "a humanidade é conduzida para uma aventura desconhecida” A solidariedade humana não é suficiente para dissipar o ódio de raça, da inimizade um dos outros, da diferença de ideologias que levam às guerras, massacres. "[...] Os processos são destruidores de um mundo antigo, aqui, multimilenar, ali, multissecular. A humanidade não consegue gerar a Humanidade [...].” (MORIN, 2001, p. 85).

Nesse caso, é necessário desenvolver a aptidão natural do espírito humano para situar todas essas informações em um contexto e num conjunto. "É preciso ensinar os métodos que permitam estabelecer as relações mútuas e as influências recíprocas entre as partes e o todo em um mundo complexo." (MORIN, 2001, p.14). É necessário, também,

promover grande remembramento dos conhecimentos oriundos das ciências naturais, a fim de situar a condição humana no mundo, dos conhecimentos derivados das ciências humanas para colocar em evidência a muldimensionalidade e a complexidade humanas, bem como integrar (na educação do futuro) a contribuição inestimável das humanidades, não somente a filosofia e a história, mas também a literatura, a poesia, as artes... (MORIN, 2001, p. 48).

A educação deve levar a "antropoética" (indivíduo - sociedade - espécie). Todo desenvolvimento humano deve compreender o desenvolvimento conjunto das autonomias individuais, das participações comunitárias e da consciência de pertencer à natureza humana. Além disso, é necessário o desenvolvimento de aptidões gerais da mente e do espírito que permitem melhor desenvolvimento das competências particulares ou especializadas." (MORIN, 2001, p. 39). Desse modo, todo o conhecimento deve conduzir à maturidade humana e profissional e, isto 
implica em uma mediação educativa no desenvolvimento das "energias corporais, intelectuais e espirituais.” (RUS, 2015, p.56).

\subsection{Formação humano-profissional e empregabilidade}

Sobre a formação humano-profissional de maneira especial das mulheres, também foi uma das grandes causas assumidas por Edith Stein entre as décadas de 1920 a 1930, uma vez que foi exigido de as mulheres assumirem a atuação na esfera pública, especialmente na educação, no comércio, na indústria e na saúde, sem a devida preparação. (STEIN, 1999). Ela acompanhou o surgimento da profissionalização das mulheres, preocupou-se, em propor uma formação adequada e adaptada aos diferentes contextos.

No sentido do desenvolvimento do ser humano, de sua formação profissional hoje, o desafio não é menor. Vivemos na eminência de uma grande crise socioeconômica e política, onde uma grande parcela da população mundial será relegada à massa desqualificada por não saber operar diante dos novos padrões de produção, distribuição, comunicação e geração de valor no mundo da indústria 4.0. (HARARI, 2018). Quem não está no ciclo da vida produtiva qualificada, está fora do poder de consumo, portanto, aumenta seu risco de exclusão social. Como a instituição confessional poderá incluir esses potenciais excluídos pelos mecanismos da inteligência artificial e da robotização? Este é o grande desafio das instituições educativas. Para Morin (2001, p.15), o ensino da “identidade terrena” e "o conhecimento dos desenvolvimentos da era planetária, que tendem a crescer no século XXI” se torna cada se tornará cada vez mais indispensável a cada um e a todos. Portanto, "esse deve converter-se em um dos principais objetos da educação". Para enfrentar as "incertezas”, é essencial ensinar princípios de estratégias que permitam o enfrentamento de imprevistos, inesperado e incertezas levando a modificação do seu desenvolvimento. O ensino das incertezas inclui as ciências físicas (microfísicas, termodinâmica e cosmologia), nas ciências da evolução biológica e ciências históricas. (MORIN, 2001, p.15). Ao nosso ver, é preciso que políticas educacionais insiram nos seus debates a discussão 
sobre o desenvolvimento do ser humano tanto cognitivamente, quanto afetiva e socialmente, pois esses aspectos, estão intrínsecos ao conceito de cidadania.

\subsection{Consciência como chave para o despertar o verdadeiro humano}

O ser humano tem a capacidade de saber de si, dar-se conta do momento que vive. Trata-se de uma capacidade que lhe permite compreender-se e ser si mesmo (ALES BELLO, 2016a). O ser humano é chamado a dar sentido ao seu viver, “a considerar que o corpo e a psique são uma só unidade com o espírito.” (STEIN, 2017, p.110). É a consciência que nos singulariza como seres humanos, pois nos dá a condição de saber-se como identidade única. Nesse sentido a "pessoa humana se constitui como única somente na tomada de posição diante da sua individualidade, que, por sua vez, habilita-a a sair de si e ir ao encontro dos outros." (ALFIERI, 2014, p.92). A consciência “pode ser examinada em modo essencial e estrutural como presente ao eu concreto.” (ALES BELLO, 2016a, p.18). Essa não é um lugar físico, específico e nem possui caráter espiritual ou psíquico. "É como um ponto de convergência das operações humanas, que nos permite dizer o que estamos dizendo ou fazendo e ou o que fazemos como seres humanos.” (ALES BELLO, 2017, p.43).

É pela consciência que percebemos e conhecemos o mundo. O mundo nos é dado; cabe a nós ativar nossos sentidos, mover nossa consciência para nos dar conta do que envolve a nossa interioridade. Alfieri nos lembra que

a autoconsciência da singularidade permite a síntese harmônica de todo o ser individual [...] uma pessoa é capaz de atuar no mundo de modo desperto somente quando consegue gerir o seu ser; caso contrário, estará sujeita ao domínio alheio [...] essa pessoa sem vitalidade própria, dependerá de influências externas para realizar as suas ações. (ALFIERI, 2014, p. 93).

No que diz respeito à formação integral, a Educação Superior deve contribuir para o despertar da consciência e das dimensões humana-psíquicas e espirituais do ser humano. No contexto do paradigma da complexidade, é preciso que o ser humano desconstrua determinadas crenças, para poder olhar a vida com 
outras "lentes", ou seja, é preciso reformar nosso pensamento. (MORIN, 2000). Para compreender o outro, há que se passar pela compreensão de si próprio porque eu não posso dar o que eu não tenho. O paradigma da complexidade conclama uma ação educativa mais fraterna, democrática e sensível. O professor, nas abordagens dirigidas pela complexidade, não é o proprietário do saber, torna-se um articulador, um facilitador, condutor da autonomia, da iniciativa, da liberdade do sujeito em formação. Nesse sentido,

[...] o paradigma emergente busca provocar uma prática pedagógica que ultrapasse a visão uniforme e que desencadeie a visão de rede, de teia, de interdependência, procurando interconectar vários interferentes que levem o aluno a uma aprendizagem mais significa, com autonomia, de maneira continua, como um processo de aprender a aprender para toda a vida. (BEHRENS, 2013, p. 111).

Sendo assim, o despertar do humano reclama por uma "ética da compreensão". Segundo Morin (2000, p.99), essa “é a arte de viver que nos demanda, em primeiro lugar, compreender de modo desinteressado. Demanda grande esforço, pois não pode esperar nenhuma reciprocidade. [...] A ética da compreensão pede que compreenda a incompreensão”.

\subsection{A espiritualidade como resposta ao sentido da vida}

Um dos elementos que singularizam a busca da verdade em Edith Stein consiste no reconhecimento de algo que está na essência do ser humano, na "alma da alma": desejo que incide em encontrar um sentido para a vida ${ }^{17}$, para o acesso à interioridade e a finitude. O ser humano, mesmo vivendo no tempo, aspira sempre algo que supera as dimensões do tempo. O ser humano é capaz, portanto, de apreender o a-temporal. Esta é a prova de que no ser humano estão presentes rastros do Eterno. (ALES BELLO, 2018, p.30). ${ }^{18}$ Deste modo, Stein propõe uma nova leitura do lugar do conhecimento e da racionalidade. O ser humano busca a

\footnotetext{
${ }^{17}$ Importa notar que a opção de Edith Stein por uma filosofia cristã deve-se aos estudos realizados sobre Tomás de Aquino, Santo Agostinho, Duns Escoto. Além disso, contribuiu também sua conversão ao cristianismo e a influência de autores como Jacques Maritain, Etienne Gilson e outros (ALES BELLO, 2014).

${ }^{18}$ Indicamos a leitura do livro O sentido do sagrado, de Angela Ales Bello, São Paulo: Paulus, 2018.
} 
verdade das coisas e enquanto "exerce a capacidade de filosofar [...] percebe, ao mesmo tempo, que a luz do conhecimento lhe advém do alto." (ALES BELLO, 2014, p.35).

Deste modo, Stein propõe opta pela filosofia cristã chave de interpretação e síntese entre espiritualidade cristã e mundo secular. A filósofa desenvolve uma onto-antropologia que sistematiza o itinerário do humano de busca da verdade na condição finita rumo ao infinito. A ênfase na essência infinita presente na finitude no ser humano finito, a relação empática proposta como base da constituição da pessoa faz com que as relações do eu seja o ponto de encontro com as relações intersubjetivas. O elemento fundamental para compreender a vivência do empatizar está na vida em movimento que se dispõe a captar a essência do outro ser humano no seu vivenciar próprio.

\section{A formação humana na Educação Superior}

O contexto da Educação Superior brasileira exige uma atitude de "coragem para ensinar". (PALMER, 2012). Diante do desenvolvimento científico-tecnológico, de mudança de paradigmas os profissionais da educação devem aprender a tecer redes, trabalhar de forma colaborativa, dialogar, acreditar na capacidade do ser humano, no poder da empatia e no autoconhecimento como caminho para sua formação profissional. Edith Stein (1999) propõe uma formação docente fundamentada no imperativo: "formar-se para bem formar o outro". Ao atribuir ao sujeito um lugar central no processo formativo, a autoformação se constitui como um dos processos formativos fundamentais. Nesse sentido, o processo de formação deve passar necessariamente por uma revisão significativa de suas bases constitutivas. Há tempos que na Academia vem se discutindo a respeito deste novo perfil ideal que está sendo exigido pela atual conjuntura política, econômico, social e educacional. O processo evolutivo de cada ser humano depende de uma integração de múltiplos fatores externos e internos e do livre arbítrio das pessoas: seu êxito é imperscrutável. Não há material formativo tomado do âmbito cultural ou pessoal de algum educador que possa mudar a natureza de um ser humano: 
pode somente contribuir a fazer com que ele tome uma ou outra característica dentre suas possíveis direções no processo de formação.

No tocante a essa problemática, Morin (2000) também, destaca a necessidade de se dar atenção especial aos processos de autoformação, alegando que essa dimensão tem sido a menos trabalhada e considerando-a uma das mais importantes para a conquista de uma autonomia profissional, pessoal e existencial do professor. Como princípio regulador do pensamento e da ação, a complexidade exige que repensemos a formação docente a partir de um processo de formação integral de natureza transdisciplinar e que inclui os três polos de formação: autoformação, heteroformação e ecoformação, reconhecendo a importância de sua dinâmica integrada para a vida pessoal e profissional docente. Portanto, o trabalho em sala de aula deverá envolver a razão e a emoção, a vivência de experiências socioafetivas, humanas, a fim de dar novos sentidos à formação. Segundo Palmer, "em uma cultura que despedaça os paradoxos, muitas pessoas desconhecem a rica dialética do estar a sós e do estar em comunidade." (PALMER, 2012, p. 81-82). Vencer os pensamentos dicotômicos: razão ou emoção, fatos ou sentimentos, teoria ou prática, ensino ou aprendizado, presencial ou virtual etc., são urgências de um tempo que demanda uma capacidade de pensar o complexo, o fluido, o atemporal e o não espacial. (STEIN, 2017; MORIN, 2000; SCHARMER, 2010; HARRARI, 2018, entre outros).

Logo, a sala de aula é o espaço, por excelência, para promover relações interpessoais fundadas na verdade, para formar comunidades de verdade, criar um campo fecundo de desenvolvimento da singularidade na interação com outras singularidades. A experiência educativa possibilita a maturação de nossa humanidade, pois a "comunidade da verdade, longe de ser linear, estática e hierárquica, é circular, interativa e dinâmica [...] a verdade é uma eterna conversa sobre coisas que importam, conduzida com paixão e disciplina." (PALMER, 2012, p. 119). Diante das ameaças de um contexto concorrencial no Ensino Superior, dos radicalismos políticos e religiosos (HARARI, 2018), muitas instituições de ensino deixaram-se seduzir pela lógica do mercado, fragilizando sua imagem e missão, 
enquanto outras ousaram ressignificar suas propostas educativas mantendo sua essência de espaços formativos inovadores, adequados com as diferentes culturas. Diante das propostas de reformulação dos currículos de formação docente, as instituições devem repensar nos direcionamentos dados a formação humana, solidária e espiritual. Edith Stein em uma de suas conferências realizadas em 1928, diz: "certas doenças da cultura moderna: a subordinação da pessoa às coisas, desenvolvimento unilateral de algumas capacidades pessoais, a fragmentação do ser interior." (STEIN, 1999, p.45), são resultantes da fragmentação do saber. A filósofa compreendeu a importância do componente curricular da ética na formação profissional. Sua proposta ética consiste em valorizar "o que está dentro e potencializa o ser humano, "uma forma interna, uma atitude de alma constante, aquilo que a consciência chama de hábito.” (STEIN, 1999, p. 55). Para Morin (2000, p. 16), a ética é um dos saberes indispensáveis à educação em os âmbitos e em todas as culturas.

\section{A fenomenologia como epistemologia do processo de formação humana}

O mundo-da-vida e da ciência, bem como o seu papel no conhecimento e o vínculo com a intersubjetividade, como proposto por Edmund Husserl (2001), apresenta uma infinidade de afecções para que se reaja à elas a todo instante. É preciso que se aprenda a "ver fenomenologicamente", isto é, redescobrir o mundo e as coisas em seu mais profundo significado: isso implica ir além dos significados determinados e impostos pela "humanidade". A fenomenologia como ciência rigorosa, coloca-se como método essencial na busca da "essência (eidos), do sentido das coisas", ou seja, do fenômeno educativo. (ALES BELLO, 2004, p.83). A contribuição da epoché, da suspenção dos conhecimentos já construídos sobre a formação docente, possibilita-nos valorizar saberes e contextos diversificados de formação. Por sua vez, a fenomenologia exige ter em conta a atitude de suspender prévios juízos e abrir-se ao fenômeno educativo que se manifesta, contextualizando-o. A fenomenologia conduz ao colhimento de uma consciência originária e ao dar-se conta de si-mesmo. Assim, o método fenomenológico com sua redução transcendental leva-nos a integrar nos processos formativos caminhos 
possíveis de edificação e construção de novos saberes. Ales Bello (2016b, p.18) considera a reflexão essencial para o resgate de uma "consciência originária": pois é por meio dela que é possível "o conhecimento do primeiro grau de consciência que acompanha as vivências". A condição de refletir possibilita, ainda, a religação dos saberes com novos contextos (universo, terra, vida, humano, cultura das humanidades e cultura científica, por meio de um núcleo organizador sistêmico cosmologia, ecologia e ciência da terra -, como também a reorganização da infraestrutura). (MORIN, 2005). Nessa perspectiva, a partir dos "atos perceptivos" e dos "atos reflexivos" é possível ativar a consciência do sujeito em formação. (ALES BELLO, 2017, p.32).

A postura fenomenológica é fundamental porque possibilita ao sujeito dar-se conta de seus atos e assumir suas vivências em seus diferentes níveis humanas, psíquicas e espirituais. (ALES BELLO, 2017, p.42). A formação do ser humano implica, ao mesmo tempo, um processo de interiorização, pois este deve ter a simesmo nas próprias mãos, considerar-se um valor perante si e aos outros. ${ }^{19}$ Assim a fenomenologia contribuiu com seu método para uma percepção apurada de si, do outro, do mundo e do transcendente e na descrição qualitativa da análise dos atos intencionais.

\section{Conclusão}

O ser humano na sua constituição enquanto pessoa é espiritual, é livre e composto por suas vivências pessoais e interpessoais. Essa relação é fundamental no que tange à totalidade da pessoa humana, ou seja, sua singularidade e individualidade. O pensamento de Edith Stein sobre os aspectos antropológicofilosóficos e teológicos da formação contribuiu para tecer um diálogo com o pensamento complexo de Edgar Morin. Ambos mostram a necessidade de promover a construção de um saber uno, pautado numa perspectiva de conjunto, levando em consideração os diferentes aspectos do todo. Edith Stein contribui para

\footnotetext{
${ }^{19}$ Edith Stein denomina "valor" uma força motivadora, de modo que se decidir é tomar posição com relação aos valores que nos afetam [...] um ato volitivo é sempre motivado no sentido de que a vontade se põe em movimento pela percepção de um valor. (RUS, 2015, p. 69).
} 
fundamentar uma formação docente humana, que desperte para a autonomia e a autoformação. A pessoa deve educar-se para a liberdade, para ser si-mesma, a fim de ter o autogoverno em todos os setores de sua vida pessoal e profissional. Filosoficamente o conceito de autonomia consiste na possibilidade do indivíduo tomar suas próprias decisões com base na sua consciência, em conhecimentos fundamentados, em pensamento refletido, em conhecimento das possíveis consequências da decisão escolhida, em seus valores e em sua cultura.

O pensamento de Edgar Morin contribui para pensarmos a educação a partir da perspectiva complexa, interligando os saberes apostando numa reforma do pensamento (como também a reforma curricular), seja realizada uma proposta de formação pautada em programas que orientem os educadores a fomentar sua vocação e valorizar sua profissão, essenciais para a concretização da reforma. Cabe a essa reforma o emprego e inteligência no/do pensamento multidimensional multirreferencial considerando o todo e a parte. É a união entre a unidade e multiplicidade que define a complexidade. Deste modo, a educação deve promover uma inteligência geral, capaz de lidar com os problemas pelo desenvolvimento de competências particulares ou especializadas e, ainda, que desenvolva a capacidade de apreender o contexto e o complexo de modo dimensional e dentro da concepção global. É preciso educar para que o sujeito saiba mobilizar seus conhecimentos em diferentes situações.

Desse modo, a formação docente requer projetos que incluam todas as dimensões do ser humano. A formação humano-integral coloca-se como grande desafio diante das diferentes forças desumanizadoras. Compreende-se que não há uma resposta pronta, tampouco consensual, há, sim, diferentes abordagens, que pretendem refletir sobre como tratar o ser humano em sua relação consigo mesmo, com os outros, com o mundo e com a transcendência. No ato educativo, o ensino e aprendizagem assumem proporções que ultrapassam a sala de aula e perduram em sua formação. Portanto, não basta prepara para a autonomia no mundo de hoje, onde a comunicação é um dos principais fatores de ação política, profissional e pessoal, é preciso dar condições aos sujeitos a fim de que possam usar seus direitos 
e ser profissionais capazes de responder as demandas da sociedade. A reflexão realizada fez emergir com maior clareza os desafios de nosso tempo: o pensar rigoroso sobre o ser humano e sua formação em uma perspectiva ontoantropológica que tenha como base uma visão de mundo e de ser humano comprometido com valores pautados na ideia de “casa comum”. (FRANCISCO, 2015).

Cabe, assim, às instituições educativas, maior ousadia e protagonismo, ensaios de vivências, que impactam com seu testemunho no contexto socialcultural-político e econômico. Trata-se de refletir sobre a importância de se transcender a transitoriedade da situação de sala de aula focada somente no conteúdo especificamente profissional e fazer dela a oportunidade para trabalhar uma formação mais completa, ou seja, mais humana, intelectual, moral e cultural. Para tal, muitos docentes precisam operar mudanças em seu sistema de valores, em suas concepções de docência, ensino e a aprendizagem. Mudanças em sua forma de ver a pessoa, o conhecimento, a sociedade, ultrapassando o que são as necessidades imediatas para trabalhar com as necessidades mais perenes de humanização e de "hominização" (MORIN, 1979).

\section{REFERÊNCIAS}

ALES BELLO, A. Edith Stein: a paixão pela verdade. Curitiba: Juruá, 2014.

ALES BELLO, A. Edmund Husserl: pensar Deus, crer em Deus. Tradução de Aparecida Turolo Garcia e Márcio Luiz Fernandes. São Paulo: Paulus, 2016a. (Coleção Mundo da vida).

ALES BELLO, A. Fenomenologia e ciências humanas. Bauru: EDUSC, 2004.

ALES BELLO, A. Il senso dell'umano: tra fenomenologia, psicologia e psicologia e psicopatologia. Roma: Castelvecchi, 2016b.

ALES BELLO, A. Introdução à fenomenologia. Belo Horizonte: SPES, 2017.

ALES BELLO, A. O sentido do sagrado. São Paulo: Paulus, 2018. 
ALFIERI, F. Pessoa humana e singularidade em Edith Stein: uma nova fundação da antropologia filosófica. São Paulo: Perspectiva, 2014.

BEHRENS, M. A. O paradigma emergente e a prática pedagógica. 6. ed. Petrópolis: Vozes, 2013.

FRANCISCO, Papa. Carta encíclica Laudato Si: sobre o cuidado da casa comum. Disponível em: http://www.vatican.va/content/francesco/pt/encyclicals/documents/papafrancesco_20150524_enciclica-laudato-si.html. Acesso em: 17 set. 2020.

HARARI, Y. N. 21 lições para o século 21. São Paulo: Companhia das Letras, 2018.

HUSSERL, E. Meditações cartesianas: introdução à fenomenologia. Tradução de Maria Gorete Lopes e Sousa. Porto: Editora Rès, 2001.

MARTÍN-SÁNCHEZ, M. A.; CÁCERES-MUÑOZ, J. La idea de universidad del cardenal John Henry Newman. Cauriensia, v. 10, p. 335-358, 2015. Disponível em: file://I:/Copia/Discos/Dialnet-LaIdeaDeUniversidadDelCardenalJohnHenryNewman5324108.pdf. Acesso em: 28 jul. 2019.

MORIN, E. A cabeça bem-feita: repensar a reforma, reformar o pensamento. Rio de Janeiro: Bertrand, 2000.

MORIN, E. As duas globalizações: complexidade e comunicação, uma pedagogia do presente. Edgar Morin, Joaquim Clotet e Juremir Machado da Silva. 3. ed. Porto Alegre: Sulina, EDIPUCRS, 2007.

MORIN, E. Introdução ao pensamento complexo. Porto Alegre: Sulina, 2005.

MORIN, E. O enigma do homem: para uma nova antropologia. 2. ed. Tradução de Fernando de Castro Ferro. Rio de Janeiro: Zahar Editores, 1979.

MORIN, E. Os sete saberes necessários à educação do futuro. Tradução de Catarina Eleonora F. da Silva; revisão técnica de Edgard de Assis Carvalho. 4. ed. São Paulo: Cortez; Brasília: UNESCO, 2001.

NEWMAN, J. H. Newman e a ideia de uma universidade. Tradução de Gilson César Cardoso de Sousa. Bauru: EDUSC, 2001.

PALMER, P. A coragem de ensinar. Vocação, as dificuldades e o potencial transformador de um professor. São Paulo: Da boa Prosa, 2012.

PASSOS, J. D. Ensino superior e magistério da Igreja. A meta da verdade e o método do diálogo. Theologica Xaveriana, v. 185, p. 1-25, 2018. Disponível em:

http://www.scielo.org.co/pdf/thxa/v68n185/o120-3649-thxa-68-185-00125.pdf. Acesso em: 19 jul. 2019.

RUMAYOR, M. John Henry Newman y su idea de la universidad en el siglo XXI. Facultad de Educación. Educación XX1, v. 22, n. 1, , 2019p. 315-333. Disponível em: 
http://revistas.uned.es/index.php/educacionXX1/article/view/20088/o. Acesso em: 19 jul. 2019.

RUS, E. de. A visão educativa de Edith Stein: aproximação a um gesto antropológico integral. Tradução de Isabelle Sanchis, Juvenal Savian Filho, Maria Cecilia Isatto Parise e Paulo Pacheco. Belo Horizonte: Artesã, 2015.

SCHARMER, C. Otto. Teoria U: como liderar pela percepção e realização do futuro emergente. São Paulo: Campus, 2010.

STEIN, E. A mulher: sua missão segundo a natureza e a graça. Tradução de Alfred J Keller. Bauru: Editora da Universidade Sagrado Coração, 1999.

STEIN, E. Formazione e sviluppo dell'individualità. Roma: Città Nuova, 2017.

STEIN, E. Introduzione alla filosofia. Traduzione dal tedesco di Anna Nmaraia Pezzella. Roma: Città Nuova Editrice, 1988.

STEIN, E. L'empatia di Edith Stein. A cura di Michele Nicoletti. 2. ed. Milano: Franco Angeli, 1992.

STEIN, E. Una ricerca sullo stato. A cura di Angela Ales Bello. Roma: Città Nuova, 1993.

VAN MANEN, M. Investigación educativa y experiencia vivida: ciencia humana para una pedagogía de la acción y la sensibilidad. Barcelona: Idea Books, 2003. 